\title{
Traveling wave based fault location for power transmission lines using morphological filters and clarke modal components
}

\author{
Elmahdi Khoudry, Abdelaziz Belfqih, Jamal Boukherouaa, Faissal Elmariami \\ Team of Electric Networks and Static Converters. Laboratory of Energy and Electrical Systems, \\ National Higher School of Electricity and Mechanics (ENSEM). Hassan II University, Morocco
}

\begin{tabular}{l}
\hline \hline Article Info \\
\hline Article history: \\
Received Aug 15, 2019 \\
Revised Oct 15, 2019 \\
Accepted Oct 23, 2019 \\
\hline Keywords: \\
Clarke transformation \\
Fault location \\
Multi-scale morphological \\
Gradient algorithm \\
Power transmission lines \\
Traveling waves \\
\hline
\end{tabular}

\begin{abstract}
This article presents a fast and accurate fault location approach for power transmission lines based on the theory of traveling waves. In fact, when faults occur, they give rise to transient voltages and currents that propagate at a speed close to that of light along the transmission line as traveling waves. Moreover, according to the superposition theorem, each of these transients is a combination of a steady-state quantity and an incremental quantity. These transient signals measured at both ends of the line are first transformed to the Clarke ( $0-\alpha-\beta$ components) components in order to categorize the type of faults, and then multi-scale morphological gradient filters are used to extract equivalent quantities to the incremental quantities to form what are called characteristic signals. These latter will be used to identify the fault location according to the proposed algorithm.
\end{abstract}

Copyright $(2020$ Institute of Advanced Engineering and Science. All rights reserved.

\section{Corresponding Author:}

Elmahdi Khoudry,

Laboratory of Energy and Electrical Systems,

National Higher School of Electricity and Mechanics (ENSEM),

Road El Jadida, Km 7, BP: 8118, Oasis-Casablanca, Morocco.

Email: e.khoudry@gmail.com

\section{INTRODUCTION}

Faults in transmission lines affect the continuity of electrical power supply, damage electrical devices, endanger the human personnel that may be exposed to live parts and sometimes can even cause natural disasters such as fires. Therefore, a rapid and precise fault location would be of great interest to power utility companies that would be able to restore quickly and accurately the well-functioning of transmission lines by fixing the problems identified at the fault points [1]. Among the most used methods in fault localization, there is the one based on the fault impedance and it uses essentially the RMS values of voltages and currents at the fundamental frequency [2-6]. This method is simple, but its precision depends on the assumptions made about the relationship between the RMS values of voltages and currents at the fault point and those at the end of the transmission line. Artificial Intelligence is also one of the methods used in fault localization, and it is based on machine learning algorithms applied to historical data [7-10]. Although it seems promising, this approach requires a huge amount of data that are not always available and therefore have to be generated according to the learning theory paradigms. The fault location method proposed in this article is based on the theory of traveling waves [11]. This latter combined with the morphological filters [12], and the Clarke modal transformation yield satisfactory results, in terms both of speed and accuracy in locating faults on overhead power transmission lines. 


\section{FAULT CHARACTERIZATION BY THE CLARKE MODAL COMPONENTS}

Being represented by its distributed parameters [13, 14], the transmission line is subjected to two regimes when exposed to a fault condition, that is, the steady-state regime that is caused by the original sources and the fault inception regime where the incremental quantities are caused by a fictious source exerted at the fault location $x_{F}$ and at the fault inception time $t_{F}=0[14,15]$. Therefore we obtain the following expressions for all $t \geq 0$ :

$$
\begin{aligned}
& \tilde{v}^{\varphi}(x, t)=v^{\varphi}(x, t)+\Delta v^{\varphi}(x, t) \\
& \tilde{\imath}^{\varphi}(x, t)=i^{\varphi}(x, t)+\Delta i^{\varphi}(x, t)
\end{aligned}
$$

Where $\varphi:=\{A, B$ ou $C\}$ represente the phases $A, B, C ; \tilde{v}^{\varphi}(x, t)$ and $\tilde{l}^{\varphi}(x, t)$ are the post-fault voltage and the post-fault current respectively; $v^{\varphi}(x, t)$ and $i^{\varphi}(x, t)$ are the steady-state voltage and the steady-state current respectively; $\Delta v^{\varphi}(x, t)$ and $\Delta i^{\varphi}(x, t)$ are the incremental voltage and the incremental current respectively. In what follows, we will focus on the characterization of the incremental quantities by the Clarke modal components since they carry the transient information throughout the fault condition. To this end, let us consider, in the fault inception regime, the representation of the portion of a transmission line that connects buses $R$ and $S$, and whose length is $L$. As shown in Figure 1, the original sources are shortcircuited and a fault has occurred at a distance $l$ from the end $R$ at the fault point $F$.

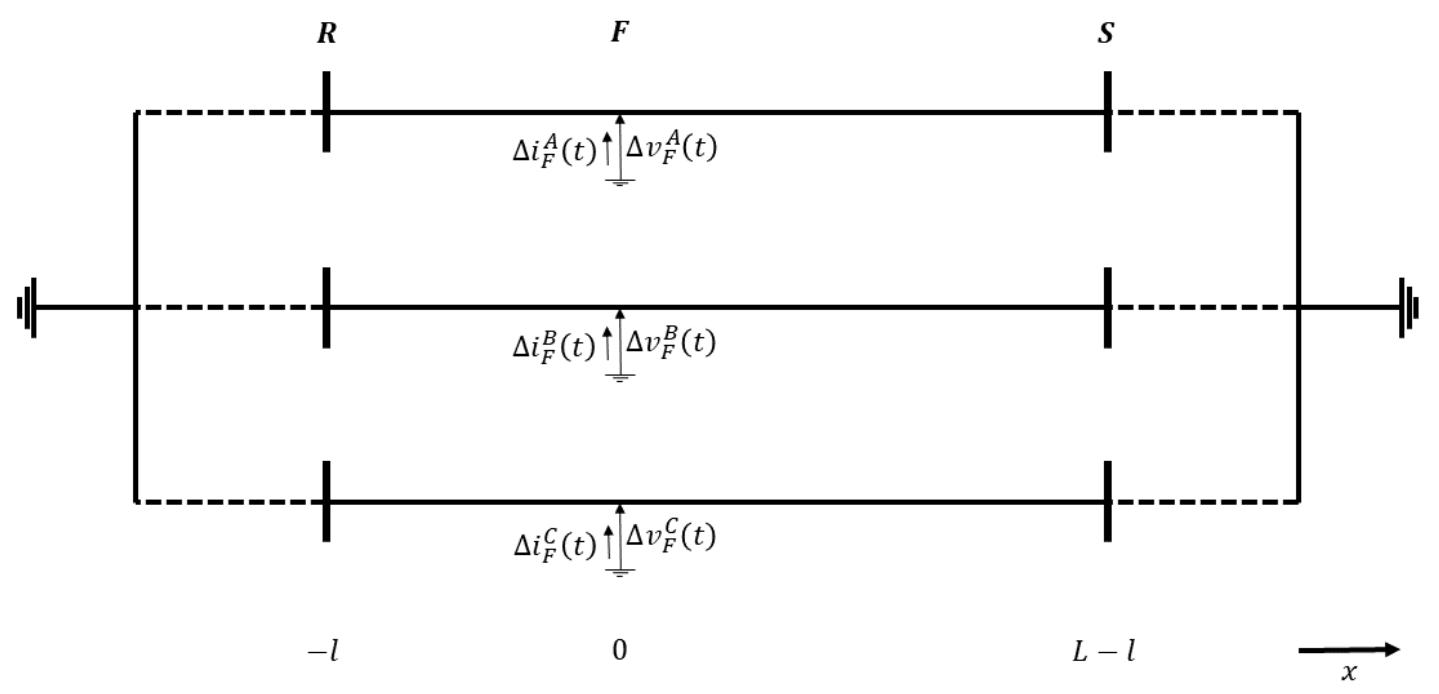

Figure 1. Representation of a transmission line in the fault inception regime

Not only the mutual coupling and capacitance between each pair of phases cause a traveling wave on a certain phase to generate also traveling waves passing through the other phases, but also cause traveling waves to distort themselves as they travel along the conductor [16]. Therefore, to analyze the propagation of traveling waves in three-phase systems, we have performed the Clarke modal transformation [17] to decompose the traveling waves on each phase into three modal decoupled traveling waves. The linear combinations relating the phase components to the modal components are given by the following expressions:

$$
\begin{aligned}
& {\left[\begin{array}{l}
\Delta v^{0}(x, t) \\
\Delta v^{\alpha}(x, t) \\
\Delta v^{\beta}(x, t)
\end{array}\right]=\frac{1}{3}\left[\begin{array}{ccc}
1 & 1 & 1 \\
2 & -1 & -1 \\
0 & \sqrt{3} & -\sqrt{3}
\end{array}\right]\left[\begin{array}{l}
\Delta v^{A}(x, t) \\
\Delta v^{B}(x, t) \\
\Delta v^{C}(x, t)
\end{array}\right]} \\
& {\left[\begin{array}{l}
\Delta i^{0}(x, t) \\
\Delta i^{\alpha}(x, t) \\
\Delta i^{\beta}(x, t)
\end{array}\right]=\frac{1}{3}\left[\begin{array}{ccc}
1 & 1 & 1 \\
2 & -1 & -1 \\
0 & \sqrt{3} & -\sqrt{3}
\end{array}\right]\left[\begin{array}{l}
\Delta i^{A}(x, t) \\
\Delta i^{B}(x, t) \\
\Delta i^{C}(x, t)
\end{array}\right]}
\end{aligned}
$$


Where $\alpha$ and $\beta$ are the subscripts used for the aerial modes of the modal incremental quantities and 0 is the subscript used for the ground mode of the modal incremental quantities. From (3) and (4) it turns out that two fault categories can be distinguished:

- Category $I$ : For the faults belonging to this category, we have $\Delta i^{0}(x, t) \neq 0$ and $\Delta i^{\alpha}(x, t) \neq 0$. This category comprises single line-to-ground (SLG) faults (AG, BG, CG) and line-to-line-to-ground (LLG) faults (ABG, BCG, CAG).

- Category II: For the faults belonging to this category, we have $\Delta i^{0}(x, t)=0$ and sometimes even $\Delta i^{\alpha}(x, t)=0$. This category comprises line-to-line (LL) faults ( $\left.\mathrm{AB}, \mathrm{BC}, \mathrm{CA}\right)$, line-to-line-to-line (LLL) fault (ABC) and line-to-line-to-line-to-ground (LLLG) fault (ABCG). the Figure 2:

Indeed, let us consider, for instance, the simplified diagram of line-to-line fault (BC) shown in

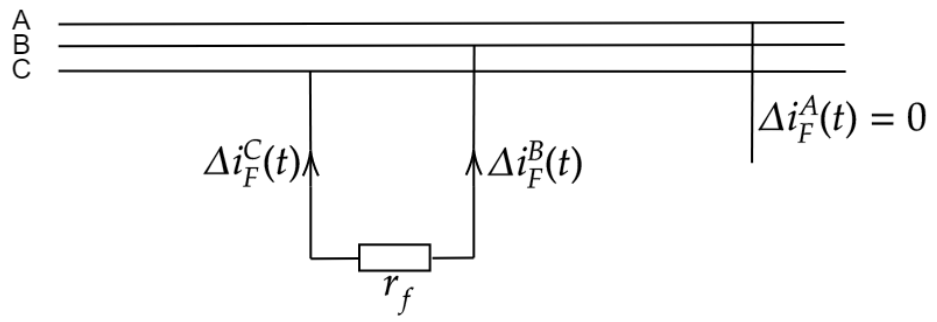

Figure 2. Simplified diagram of line-to-line fault (BC) at the fault point $F$

We have then at the fault point $\mathrm{F}$ :

$$
\begin{aligned}
& \Delta i_{F}^{A}(t)=0 \\
& \Delta i_{F}^{B}(t)=-\Delta i_{F}^{C}(t)
\end{aligned}
$$

The Clarke matrix being invertible, we obtain from relations (4), (5) et (6) the following expressions:

$$
\begin{aligned}
& \Delta i_{F}^{0}(t)+\Delta i_{F}^{\alpha}(t)=0 \\
& 2 \Delta i_{F}^{0}(t)-\Delta i_{F}^{\alpha}(t)=0
\end{aligned}
$$

From (7) and (8) we deduce that:

$$
\Delta i_{F}^{0}(t)=\Delta i_{F}^{\alpha}(t)=0
$$

\section{PROPOSED APPROACH FOR FAULT LOCATION}

According to the traveling wave theory [18-20], the voltage and current waves produced by the fault point $\mathrm{F}$ travel along both sides of the line at speed $u_{m}$ depending on the mode $m:=\{0, \alpha, \beta\}$ considered as shown in Figure 3. Thus, we have:

- Two forward waves $\left(\Delta v_{F}^{m}\left(t-x / u_{m}\right), \Delta i_{F}^{m}\left(t-x / u_{m}\right) / 2=\Delta v_{F}^{m}\left(t-x / u_{m}\right) / Z_{c}\right)$ moving towards the end $S$.

- Two backward waves $\left(\Delta v_{F}^{m}\left(t+x / u_{m}\right), \Delta i_{F}^{m}\left(t+x / u_{m}\right) / 2=\Delta v_{F}^{m}\left(t+x / u_{m}\right) / Z_{c}\right)$ moving towards the end $R$.

Thus, the modal incremental quantities can be expressed as follows:

$$
\begin{aligned}
& \Delta v^{m}(x, t)=\mathbf{1}\left\{x \geq 0 \text { et } 0 \leq t<\frac{L-l}{u_{m}}\right\} \Delta v_{F}^{m}\left(t-\frac{x}{u_{m}}\right)+\mathbf{1}\left\{x<0 \text { et } 0 \leq t<\frac{l}{u_{m}}\right\} \\
& \Delta v_{F}^{m}\left(t+\frac{x}{u_{m}}\right) \\
& \Delta i^{m}(x, t)=\frac{\mathbf{1}\left\{x \geq 0 \text { et } 0 \leq t<\frac{L-l}{u_{m}}\right\} \Delta i_{F}^{m}\left(t-\frac{x}{u_{m}}\right)}{2}+\frac{\mathbf{1}\left\{x \leq 0 \text { et } 0 \leq t<\frac{l}{u_{m}}\right\} \Delta i_{F}^{m}\left(t+\frac{x}{u_{m}}\right)}{2}
\end{aligned}
$$


Where $Z_{c}$ is the surge impedance of the portion $R S$ of the transmission line, and $\mathbf{1}\{$.$\} the indicator function$ that is equal to 1 when its argument is true.

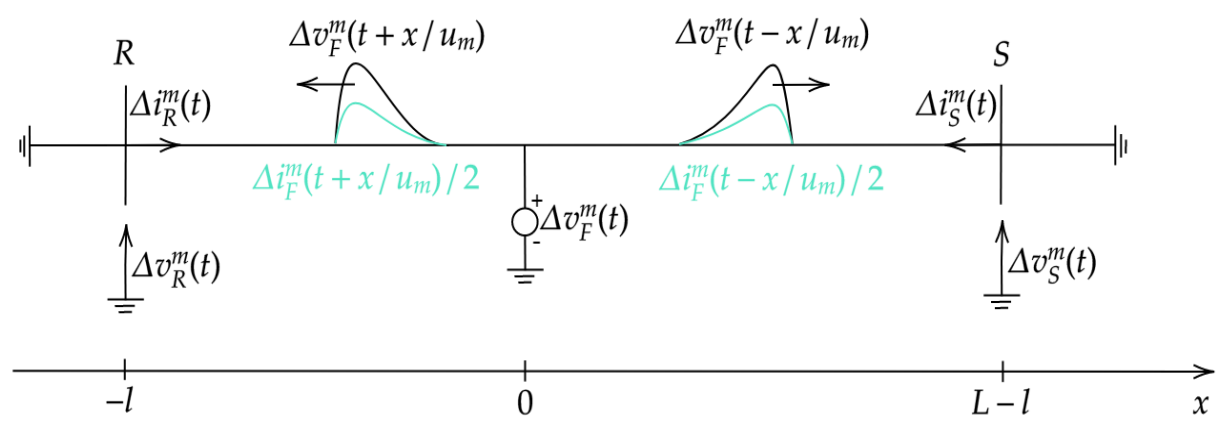

Figure 3. Propagation of modal waves along the transmission line portion RS in the fault inception regime

From expressions (10) and (11) we deduce the values of the modal incremental quantities at the ends $R$ and $S$ that are respectively distant by $l$ and $L-l$ from the fault point $F$ considered as the origin of the $\mathrm{x}$-axis.

$$
\begin{aligned}
& \Delta v_{R}^{m}(t)=\left(1+\Gamma_{m}^{R}\right) \Delta v_{F}^{m}\left(t-\frac{l}{u_{m}}\right) \\
& \Delta v_{S}^{m}(t)=\left(1+\Gamma_{m}^{S}\right) \Delta v_{F}^{m}\left(t-\frac{L-l}{u_{m}}\right) \\
& \Delta i_{R}^{m}(t)=-\left(1-\Gamma_{m}^{R}\right) \Delta i_{F}^{m}\left(t-\frac{l}{u_{m}}\right) \\
& \Delta i_{S}^{m}(t)=-\left(1-\Gamma_{m}^{S}\right) \Delta i_{F}^{m}\left(t-\frac{L-l}{u_{m}}\right)
\end{aligned}
$$

Where $\Gamma_{m}^{R}$ and $\Gamma_{m}^{S}$ are the reflexion coefficients at the ends $R$ and $S$ respectively. Thus, we deduce that the arrival time of the first modal incremental voltage wave front and the first modal incremental current wave front from the fault location to the end $R$ is $t_{R}^{m}=l / u_{m}$. We deduce also that the arrival time of the first modal incremental voltage and current wave fronts from the fault location to the end $S$ is $t_{S}^{m}=(L-l) / u_{m}$ as shown in Figure 4 and Figure 5. Therefore, for the faults belonging to category $I$, we consider only the arrival times of the $\alpha$ and 0 components of the modal incremental quantities at the end $R$.

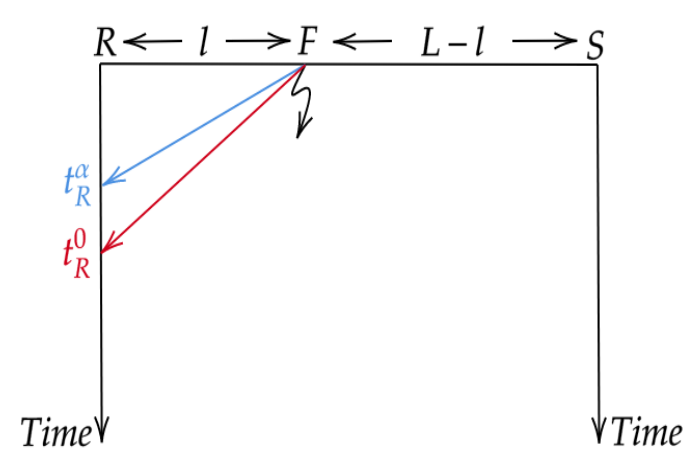

Figure 4. Arrival times of the $\alpha$ and 0 components of the modal incremental quantities at the end $R$

$$
\begin{aligned}
t_{R}^{0} & =\frac{l}{u_{0}} \\
t_{R}^{\alpha} & =\frac{l}{u_{\alpha}}
\end{aligned}
$$


From (16) and (17) we obtain :

$$
l=\frac{t_{R}^{0}-t_{R}^{\alpha}}{\frac{1}{u_{0}}-\frac{1}{u_{\alpha}}}
$$

and concerning the faults belonging to category $I I$, we consider only the arrival times of the $\beta$ component of the modal incremental quantities at the ends $R$ and $S$.

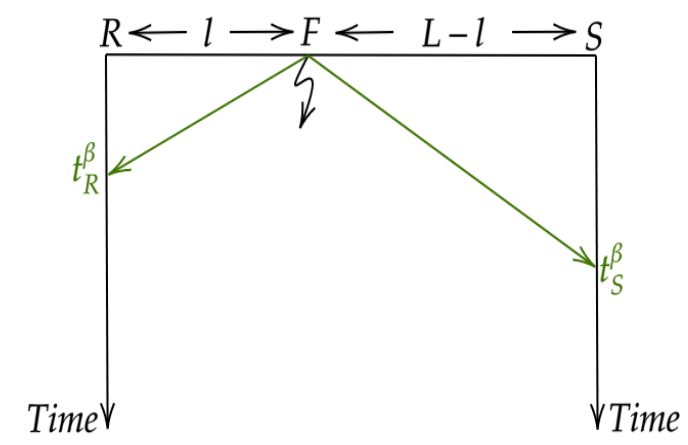

Figure 5. Arrival times of the $\beta$ component of the modal incremental quantities at the ends $R$ and $S$

$$
\begin{aligned}
& t_{R}^{\beta}=\frac{l}{u_{\beta}} \\
& t_{S}^{\beta}=\frac{L-l}{u_{\beta}}
\end{aligned}
$$

From (19) and (20) we obtain :

$$
l=\frac{L+u_{\beta}\left(t_{R}^{\beta}-t_{S}^{\beta}\right)}{2}
$$

\section{MULTI-SCALE MORPHOLOGICAL GRADIENT ALGORITHM}

In this section we will present the level $s$ multi-scale morphological gradients [21] of the modal voltages and currents $\left(\rho_{S}^{\tilde{v}_{R}^{m}}[n], \rho_{S}^{\tilde{v}_{S}^{m}}[n], \rho_{S}^{\tilde{i}_{R}^{m}}[n], \rho_{S}^{\tilde{i}_{S}^{m}}[n]\right)$ that will, from now on, represent and replace the modal incremental voltages and currents $\left(\Delta v_{R}^{m}, \Delta v_{S}^{m}, \Delta i_{R}^{m}, \Delta i_{S}^{m}\right)$ [22-24]. To this end, let us consider a digital signal $x[n]$ whose length is $l_{x}$, and the level $s$ dyadic length $l_{s}=2^{s-1} l_{1}$ of the operators $\max$ and $\min$, where $l_{1}$ is the level 1 length of the operators $\max$ and $\min$ to be preset. The level $s$ multi-scale morphological gradient of $x[n]$ can be presented as follows:

\section{Algorithm A1}

1. Start.

2. Get $x[n]$ and $l_{x}$.

3. $\rho_{0}[n]=x[n]$.

4. Determine $l_{1}$ and $s$.

5. $k=1$.

6. While $k<s$ :

6.1. Compute $\delta_{k}^{+}[n]$ using (22).

6.2. Compute $\varepsilon_{k}^{+}[n]$ using (23) .

6.3. Compute $\delta_{k}^{-}[n]$ using (24).

6.4. Compute $\varepsilon_{k}^{-}[n]$ using (25).

6.5. Compute $\rho_{k}^{+}[n]$ using (26).

6.6. Compute $\rho_{k}^{-}[n]$ using (27).

6.7. Compute $\rho_{k}[n]$ using (28) .

7. End While.

8. End. 
Where:

$\delta_{s}^{+}[n]$ is the level $s$ flat positive dilation:

$$
\delta_{s}^{+}[n]=\left\{\begin{array}{c}
\max _{1 \leq m \leq l_{s}}\left\{\rho_{s-1}[n+m]\right\} 1 \leq n \leq l_{x}-l_{s}+1 \\
\rho_{s-1}[n] l_{x}-l_{s}+2 \leq n \leq l_{x}
\end{array}\right.
$$

$\varepsilon_{s}^{+}[n]$ is the level $s$ flat positive erosion:

$$
\varepsilon_{s}^{+}[n]=\left\{\begin{array}{c}
\rho_{s-1}[n] 1 \leq n \leq l_{s}-1 \\
\min _{1 \leq m \leq l_{s}}\left\{\rho_{s-1}[n+m]\right\} l_{s} \leq n \leq l_{x}
\end{array}\right.
$$

$\delta_{s}^{-}[n]$ is the level $s$ flat negative dilation:

$$
\delta_{s}^{-}[n]=\left\{\begin{array}{c}
\rho_{s-1}[n] 1 \leq n \leq l_{s}-1 \\
\max _{1 \leq m \leq l_{s}}\left\{\rho_{s-1}[n+m]\right\} l_{s} \leq n \leq l_{x}
\end{array}\right.
$$

$\varepsilon_{s}^{-}[n]$ is the level $s$ flat negative erosion:

$$
\varepsilon_{s}^{-}[n]=\left\{\begin{array}{c}
\min _{1 \leq m \leq l_{s}}\left\{\rho_{s-1}[n+m]\right\} 1 \leq n \leq l_{x}-l_{s}+1 \\
\rho_{s-1}[n] l_{x}-l_{s}+2 \leq n \leq l_{x}
\end{array}\right.
$$

$\rho_{s}^{+}[n]$ is the level $s$ flat positive gradient:

$$
\rho_{s}^{+}[n]=\delta_{s}^{+}[n]-\varepsilon_{s}^{+}[n]
$$

$\rho_{s}^{-}[n]$ is the level $s$ flat negative gradient:

$$
\rho_{s}^{-}[n]=\varepsilon_{s}^{-}[n]-\delta_{s}^{-}[n]
$$

$\rho_{S}[n]$ is the level $s$ flat gradient:

$$
\rho_{s}[n]=\rho_{s}^{+}[n]+\rho_{s}^{-}[n]
$$

\section{PROPOSED FAULT LOCATION ALGORITHM}

Before presenting the proposed algorithm, we will first present the algorithm by which we can detect the sample index $n_{\max }^{m}$ corresponding to the local modulus maximum of the characteristic signal $\left|\rho_{s}^{\tilde{v}_{R}^{m}}[n] \rho_{s}^{i_{R}^{m}}[n]\right|$. For a given mode $m:=\{\alpha, \beta$ or 0$\}$ and node $:=\{R$ or $S\}, T h_{m}>0$ being the empirical threshold of the characteristic signal above which the presence of the fault inception regime is indicated, we have the following algorithm:

Algorithm A2

1. Start.

2. $i=1, n_{\text {max }}^{\text {max }}=0$

3. While $\left|\rho_{s}^{\tilde{v}_{\text {node }}^{m}}[i] \rho_{s}^{\tilde{\rho}_{\text {node }}^{m}}[i]\right| \leq T h_{m}$

$$
3.1 i=i+1
$$

4. End While.

5. $n=i$

6. While $\left|\rho_{s}^{\tilde{v}_{\text {node }}^{m}}[n+1] \rho_{s}^{\tilde{i}_{\text {node }}^{m}}[n+1]\right|>\left|\rho_{s}^{\tilde{v}_{\text {node }}^{m}}[n] \rho_{s}^{\tilde{i}_{\text {node }}^{m}}[n]\right|$

$6.1 n=n+1$

7. End While.

8. If $\rho_{s}^{\tilde{v}_{\text {node }}^{m}}[n] \rho_{s}^{\tilde{i}_{\text {node }}^{m}}[n]<0$ :

9. $n_{\text {max }}^{\text {m,node }}=n$

10. End $I f$.

11. End. 
It should be noted that step 8 of algorithm A2 will be used in algorithm A3 to verify whether the fault is internal or external [25]. The fault is internal when, for any mode $m$, $\rho_{S}^{\tilde{v}_{R}^{m}}\left[n_{\max }^{m, R}\right] \rho_{S}^{\tilde{i}_{R}^{m}}\left[n_{\max }^{m, R}\right]<-T h_{m}$ and $\rho_{S}^{\tilde{v}_{S}^{m}}\left[n_{\max }^{m, S}\right] \rho_{S}^{\tilde{l}_{S}^{m}}\left[n_{\max }^{m, S}\right]<-T h_{m}$. Finally, the proposed algorithm is presented by algorithm A3:

Algorithm A3

1. Start.

2. Define the sampling rate $f_{s}$ in $\mathrm{MHz}$.

3. $k=0$

4. For $j=1+600 k f_{s}$ to $(1200+600 k) f_{s}$

4.1 For all modes $m$, compute and store $\tilde{v}_{R}^{m}[j], \tilde{\imath}_{R}^{m}[j], \tilde{v}_{S}^{m}[j], \tilde{\imath}_{S}^{m}[j]$ using (3) and (4).

5. End for.

6. For all modes $m$, extract $\rho_{S}^{\tilde{v}_{R}^{m}}[j], \rho_{S}^{\tilde{i}_{R}^{m}}[j], \rho_{S}^{\tilde{v}_{S}^{m}}[j]$ and $\rho_{S}^{\tilde{i}_{S}^{m}}[j]$ from $\tilde{v}_{R}^{m}[j], \tilde{i}_{R}^{m}[j], \tilde{v}_{S}^{m}[j]$ and $\tilde{l}_{S}^{m}[j]$ respectively using algorithm $\mathrm{A} 1$.

7. For all modes $\mathrm{m}$, run algorithm $\mathrm{A} 2$ for nodes $R$ and $S$ to obtain the indices $n_{\max }^{m, R}$ et $n_{\max }^{m, S}$ corresponding respectively to the local modulus maxima of $\left|\rho_{S}^{\tilde{v}_{R}^{m}}[n] \rho_{S}^{\tilde{i}_{R}^{m}}[n]\right|$ and $\left|\rho_{S}^{\tilde{v}_{S}^{m}}[n] \rho_{S}^{\tilde{i}_{S}^{m}}[n]\right|$

8. If $n_{\text {max }}^{\alpha, R}+n_{\text {max }}^{\beta, R}=0$ or $n_{\text {max }}^{\alpha, S}+n_{\text {max }}^{\beta, S}=0$ :

$8.1 k=k+1$

8.2 go back to step 4.

9. End If.

10. Else If $n_{\text {max }}^{0, R}=0$ and $n_{\text {max }}^{\beta, R} \neq 0$ :

10.1 Obtain $l$ by remplacing $t_{R}^{\beta}$ and $t_{S}^{\beta}$ with $\frac{n_{\max }^{\beta, R}}{f_{S}}$ and $\frac{n_{\max }^{\beta, S}}{f_{S}}$ respectively in relation (21).

11. End Else If .

12. Else if $n_{\max }^{0, R} \neq 0$ :

12.1 Obtain $l$ by replacing $t_{R}^{0}$ and $t_{R}^{\alpha}$ with $\frac{n_{\max }^{0, R}}{f_{S}}$ et $\frac{n_{\max }^{\alpha, R}}{f_{S}}$ respectively in relation (18).

13. End Else If.

14. End.

\section{SIMULATION RESULTS AND DISCUSSIONS}

To asses the efficiency of the proposed method for fault location, we considered a transmission line on which internal faults were simulated on the portion $R S$ as shown in Figure 6. The voltage and current signals observed at ends $R$ and $S$ were sampled at a rate of $1 \mathrm{MHz}$ and then processed through algorithm A3. As stated in step 4 of algorithm A3, we regarded a $1200 \mu$ s time-based window whose sliding interval is $600 \mu \mathrm{s}$. In regards to algorithm $\mathrm{A} 1$, we took $l_{1}=8$, which is equivalent to a sliding sub-window that covers a period of $8 \mu \mathrm{s}$ and moves continuously by one sample inside the main window [25].

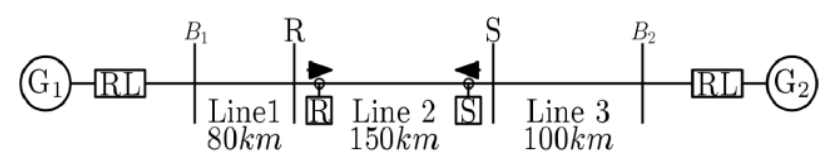

Figure 6. Simulation model

To verify the performance of the proposed approach, we analyzed the influence of the fault type, the fault resistance, the fault inception angle, and the sampling rate on the fault location error $\varepsilon \%$ given by the following expression:

$$
\varepsilon \%=\frac{|l-\hat{l}|}{L} \times 100
$$

Where:

- $\quad l$ : The actual distance between end $R$ and the fault point.

- $\quad \hat{l}$ : The estimated distance between end $R$ and the fault point.

- $\quad L:$ The length of the portion $R S$. 
Before giving a numerical example, it should be noted that $u_{\alpha}=u_{\beta}=2.9304 \cdot 10^{5} \mathrm{~km} . \mathrm{s}^{-1}$ and $u_{0}=2.2263 \cdot 10^{5} \mathrm{~km} \cdot \mathrm{s}^{-1}$. Thus, as shown in Figure 7 , for a fault belonging to category $I$ that actually occurred at $25 \mathrm{~km}$ from end $R$, we have according to the blue graph $t_{R}^{\alpha}=4.237 \mathrm{~ms}$, and to the red graph $t_{R}^{0}=4.264 \mathrm{~ms}$. Therefore, we obtain according to algorithm A3 and (18):
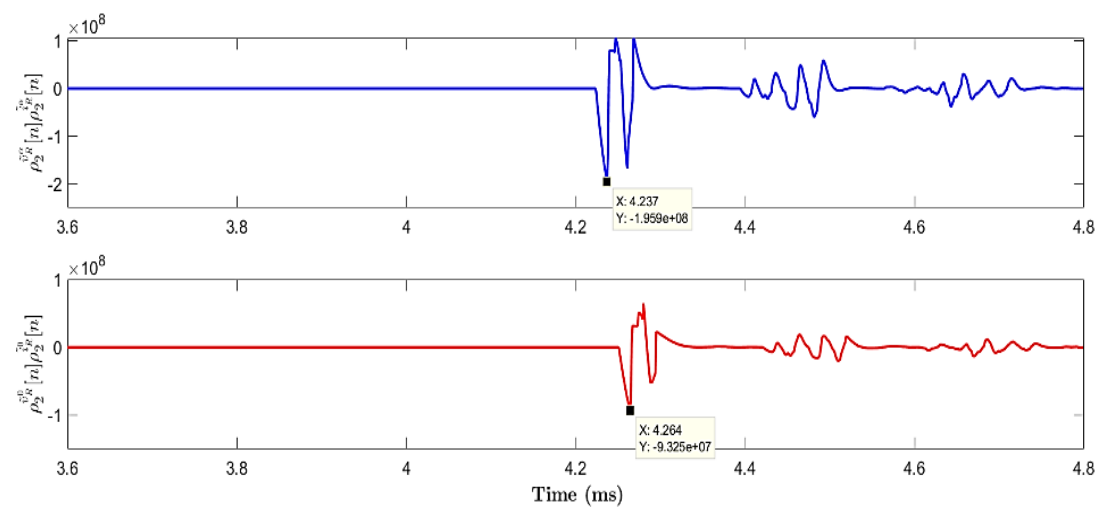

Figure 7. Characteristic signal: mode $\alpha$ (blue) and mode 0 (red)

$$
\hat{l}=\frac{(4.264-4.237) \cdot 10^{-3}}{1.0792 \cdot 10^{-6}} \approx 25.0185 \mathrm{~km}
$$

We have consequently from $(29), \varepsilon \%=0.012 \%$. We would proceed in the same manner for the faults belonging to category II by taking into account their specific fault location parameters.

\subsection{Influence of the fault type}

In order to study the effect of fault type on the fault location error, we simulated all types of faults (SLG, LLG, LL, LLL, LLLG) along the portion $R S$, while fixing the fault resistance in $2 \Omega$ and the fault inception angle in $90^{\circ}$. The distribution of fault location errors obtained by algorithm A3 is represented in the Figure 8.

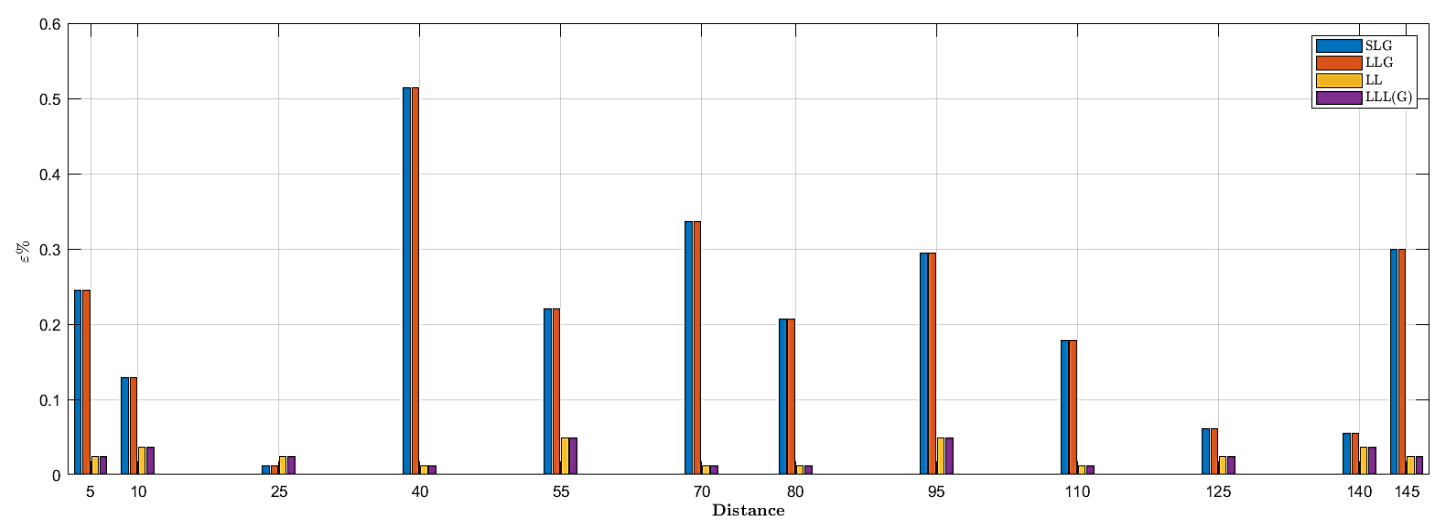

Figure 8. Distribution of the fault location errors according to the fault type

We observe that the distribution of fault location errors is the same within the same category but, on the contrary, it differs from one category to another. Indeed, SLG and LLG faults that belong to category $I$ have the same fault location error whatever the distance considered, and the same thing for LL and LLL(G) faults that belong to category $I I$. Nevertheless, the fault location errors of category $I$ faults are higher than the fault location errors of category $I I$ faults, and that comes down to the trade-off between the fault location accuracy and the fault location rapidity. Although it is less precise, the location of category $I$ faults is fast 
since it is based on single-ended fault location techniques that require only one measurement point (end $R$ ); whereas the location of category $I I$ faults is more precise, but is less rapid since it is based on double-ended fault location techniques that require two measurement points (end $R$ and end $S$ ) exchanging information with a reference point (end $R$ ) or a SCADA system with a certain latency that should be reduced using efficient internet based communication protocols [26, 27]. Out of this analysis, we conclude that the proposed fault location approach is sensitive to the fault category, but within the same category, it insensitive to the types of faults and to the phases $\varphi$ involved in the fault process. In other words, whatever the phases affected, the faults belonging to the same category give the same fault location error distribution.

\subsection{Influence of the fault resistance}

To study the impact of the fault resistance, we compared the distribution of the fault location errors along the portion $R S$ of both fault categories using two different fault resistances $(2 \Omega$ and $100 \Omega)$. As shown in Figures 9 and 10, within the same category, the proposed fault location algorithm is insensitive to the fault resistance since the distribution of the fault location errors remains the same for any fault resistance. In addition, the proposed algorithm is very precise since for both categories the observed errors are smaller than $0.6 \%$.

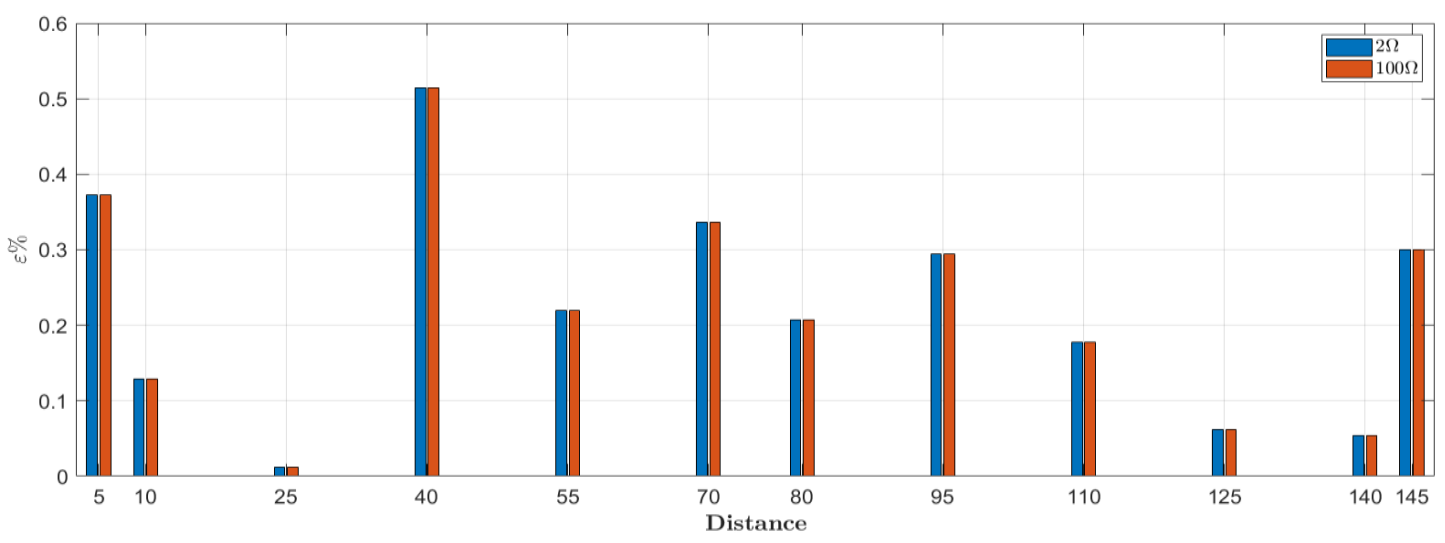

Figure 9. Distribution of the fault location errors of category $I$ faults according to the fault resistance

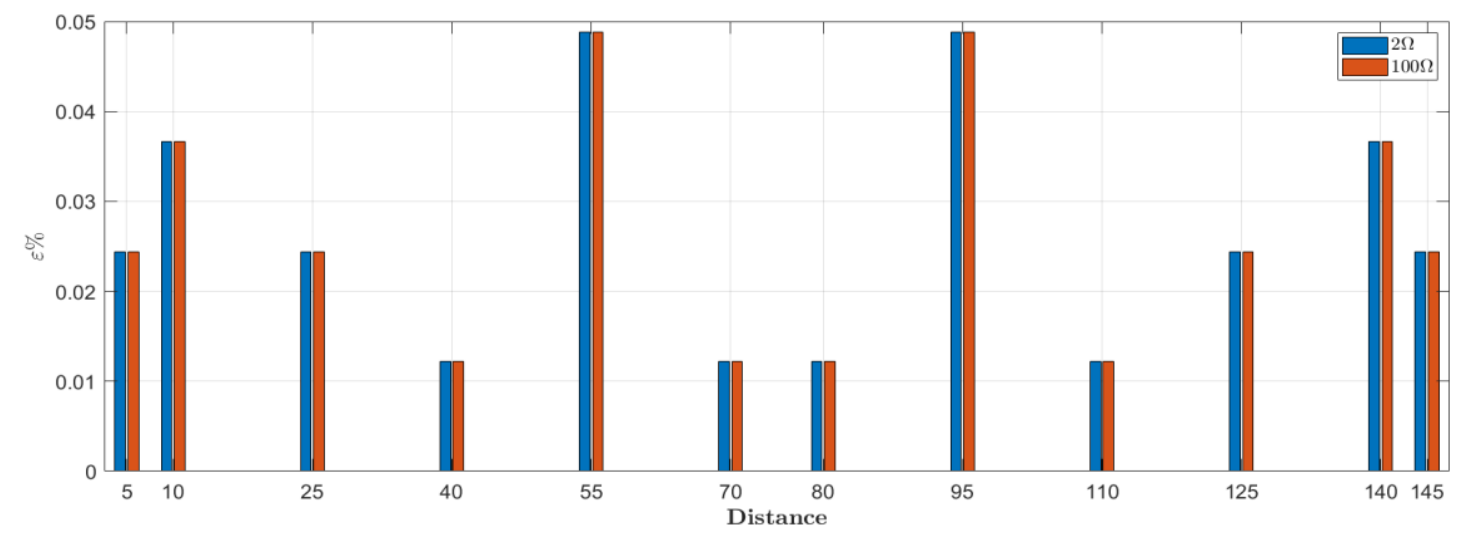

Figure 10. Distribution of the fault location errors of category II faults according to the fault resistance

\subsection{Influence of the fault inception angle}

For the purpose of studying the influence of the fault inception angle on the fault location error, faults of both categories have been triggered along the portion $R S$ at fault inception angles $60^{\circ}, 30^{\circ}$ and $0^{\circ}$. From Figures 11 and 12, it appears that, within the same fault category, the distribution of the fault location errors does not vary from one fault inception angle to another. Moreover, the maximum error concerning category $I$ faults is about $0.5 \%$ and the maximum error of category $I I$ faults is about $0.07 \%$. It can be concluded that the proposed method for fault location is precise and insensitive to fault inception angles. 


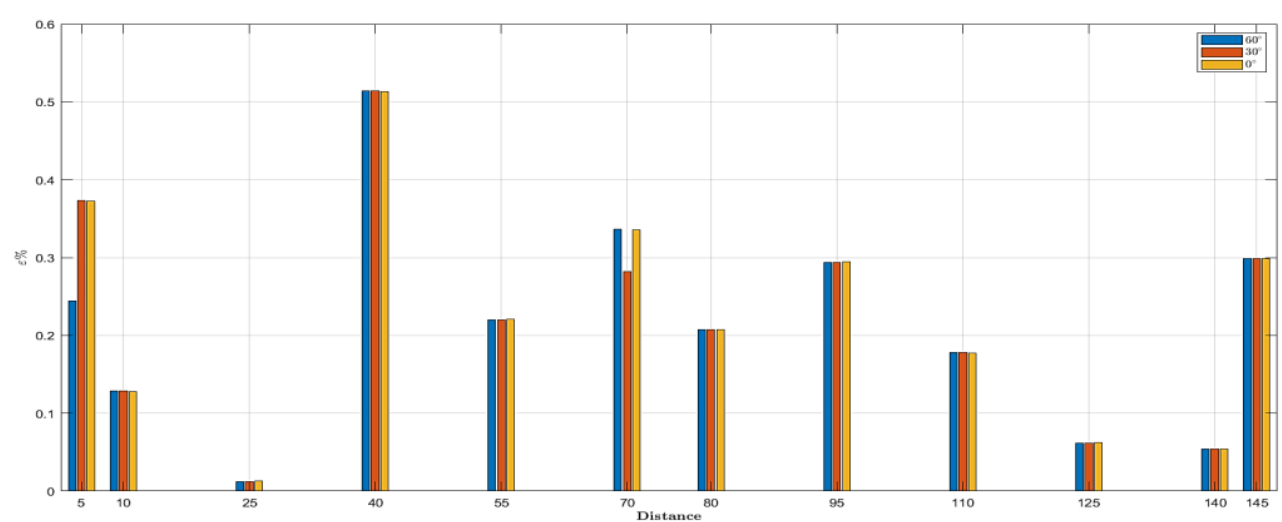

Figure 11. Distribution of the fault location errors of category $I$ faults according to the fault inception angle

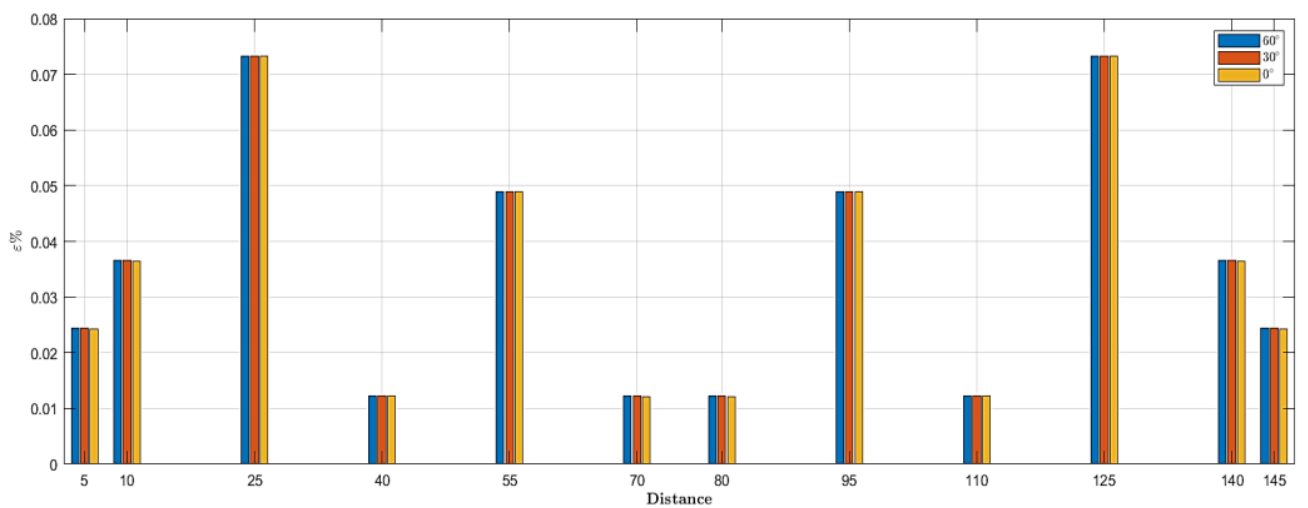

Figure 12. Distribution of the fault location errors of category $I I$ faults according to the fault inception angle

\subsection{Influence of the sampling rate}

In order to study the impact of the sampling rate on the distribution of the fault location errors, we used sampling rates of $1 \mathrm{MHz}$ and $0.5 \mathrm{MHz}$ while keeping, for the faults of both categories, the fault resistance at $2 \Omega$ and the fault inception angle at $90^{\circ}$. According to Figures 13 and 14, it can be observed that, for both fault categories, the fault location precision decreases with the decrease of the sampling rate. Indeed, the fault location errors corresponding to the sampling rate $0.5 \mathrm{MHz}$ and represented by the red bars are much higher than those corresponding to the sampling rate $1 \mathrm{MHz}$ and represented by the blue bars. We deduce that the proposed fault location algorithm is very sensitive to the sampling rate and that the higher is the sampling rate, the better is the fault location precision.

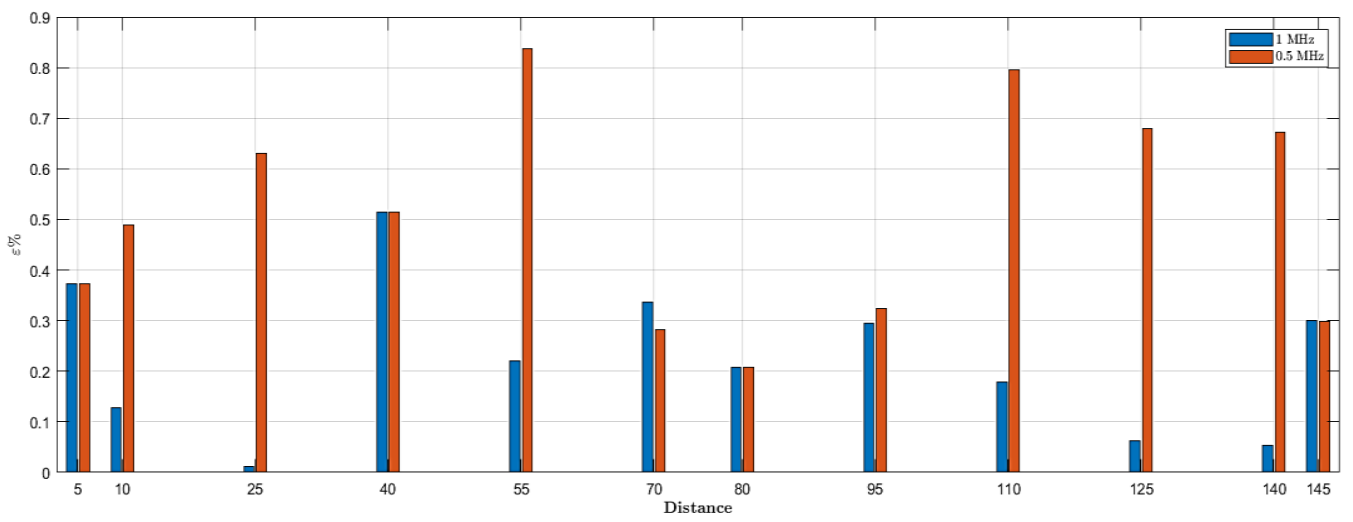

Figure 13. Distribution of the fault location errors of category $I$ faults according to the sampling rate 


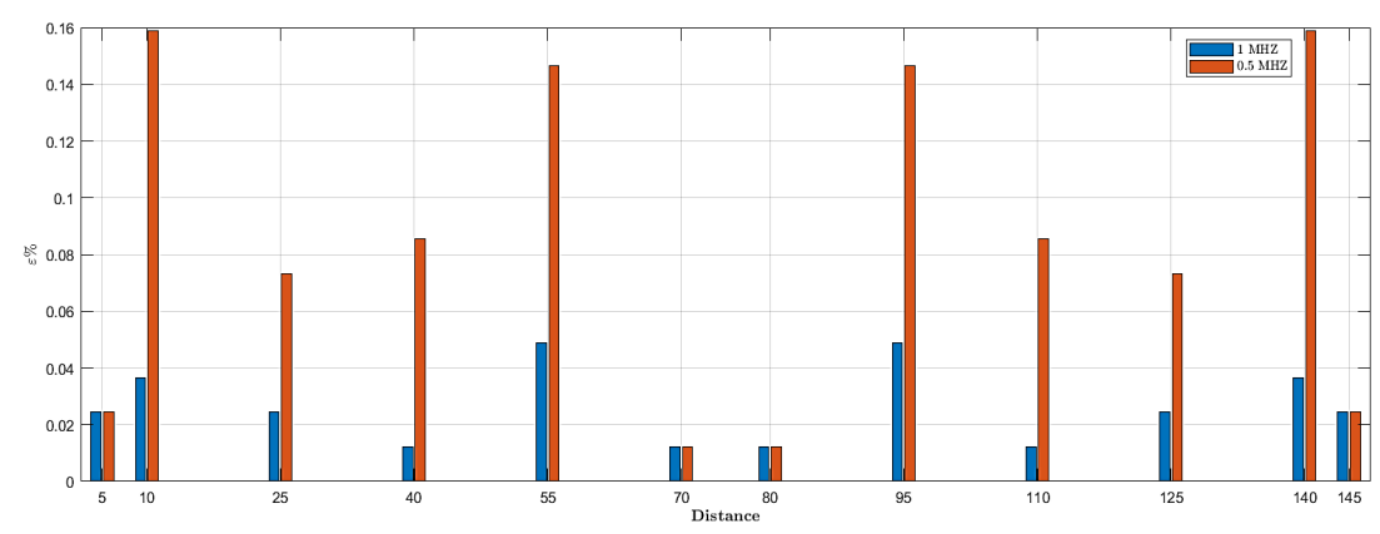

Figure 14. Distribution of the fault location errors of category $I I$ faults according to the sampling rate

\section{CONCLUSION}

In this article, we presented another fault location approach based on a combination between the traveling wave theory, the Clarke modal transformation and the multi-scale morphological filtering. This approach gathers two fault location techniques, where one is based on single-ended measurements of voltage and current from which the $\alpha$ and 0 components of the characteristic signals corresponding end $R$ were extracted, and the other is based on double-ended measurements of voltage and current from which the $\beta$ component of the characteristic signals corresponding to ends $R$ and $S$ were extracted. The analysis showed that for all simulation cases and for both fault categories the maximum fault location error is about $1 \%$ and consequently, even if it is sensitive to the sampling rate, the proposed approach is precise and fast as well as insensitive to the fault type, the fault resistance and the fault inception angle.

\section{REFERENCES}

[1] N. Gana, N. Ab Aziz, Z. Ali, H. Hashim, B. Yunus., "A Comprehensive Review of Fault Location Methods for Distribution Power System," Indonesian Journal of Electrical Engineering and Computer Science, vol. 6(1), pp. 185, 2017. Available: 10.11591/ijeecs.v6.i1.pp185-192.

[2] F. Aboshady, D. Thomas, M. Sumner., "A new single end wideband impedance based fault location scheme for distribution systems," Electric Power Systems Research, vol. 173, pp. 263-270, 2019.

[3] T. Takagi, Y. Yamakoshi, M. Yamaura, R. Kondow and T. Matsushima., "Development of a New Type Fault Locator Using the One-Terminal Voltage and Current Data," IEEE Power Engineering Review, vol. 2(8), pp. 59-60, 1982. Available: 10.1109/mper.1982.5519781.

[4] Edmund O Schweitzer., "A review of impedance-based fault locating experience," Proceedings of the 15th Annual Western Protective Relay Conference, Spokane, WA, vol. 24, pp. 27, 1988.

[5] M. Gabr, D. Ibrahim, E. Ahmed, M. Gilany., "A new impedance-based fault location scheme for overhead unbalanced radial distribution networks," Electric Power Systems Research, vol. 142, pp. 153-162, 2017. Available: 10.1016/j.epsr.2016.09.015.

[6] M. H. Rawa., "Characteristic and Surge Impedance Variation Impact on Transmission Line Performance," International Journal of Electrical and Computer Engineering (IJECE), vol. 8(4), pp. 2602, 2018.

[7] N. Jamili, M. Adzman, S. Rahim, S. Zali, M. Isa, H. Hanafi, "Evaluation of earth fault location algorithm in medium voltage distribution network with correction technique," International Journal of Electrical and Computer Engineering (IJECE), vol. 9(3), pp. 1987, 2019. Available: 10.11591/ijece.v9i3.pp1987-1996.

[8] A. Abdullah., "Ultrafast transmission line fault detection using a dwt-based ann," IEEE Transactions on Industry Applications, vol. 54(2), pp. 1182-1193, 2018.

[9] E. Khoudry, A. Belfqih, M. N. Dazahra., "Neural network approach for fault detection in substations," in Proceedings of the 2Nd International Conference on Big Data, Cloud and Applications, ser. BDCA'17, New York, NY, USA: ACM, pp. 11:1-11:6, 2017. [Online]. Available: http://doi.acm.org/10.1145/3090354.3090365

[10] V Ashok, A Yadav, CC Antony, KK Yadav, UK Yadav, Sandeep Kumar Sahu., "An intelligent fault locator for 400-kv double-circuit line of Chhattisgarh state: a comparative study," Soft Computing in Data Analytics, pp. 39-49, 2019.

[11] M. Shafiullah, M. Abido, Z. Al-Hamouz, "Wavelet-based extreme learning machine for distribution grid fault location," IET Generation, Transmission \& Distribution, vol. 11(17), pp. 4256-4263, 2017. Available: 10.1049/ietgtd.2017.0656.

[12] E. Schweitzer, A. Guzman, M. Mynam, V. Skendzic, B. Kasztenny, S. Marx., "Protective Relays with Traveling Wave Technology Revolutionize Fault Locating", IEEE Power and Energy Magazine, vol. 14(2), pp. 114-120, 2016. Available: 10.1109/mpe.2016.2543123. 
[13] P. Maragos and R. Schafer, "Morphological filters-Part I: Their set-theoretic analysis and relations to linear shiftinvariant filters," in IEEE Transactions on Acoustics, Speech, and Signal Processing, vol. 35(8), pp. 1153-1169, Aug. 1987.

[14] A. Gopalakrishnan, M. Kezunovic, S. M. McKenna, D. M. Hamai, "Fault location using the distributed parameter transmission line model," in IEEE Transactions on Power Delivery, vol. 15(4), pp. 1169-1174, 2000.

[15] A. Johns., "New ultra-high-speed directional comparison technique for the protection of ehv transmission lines," in IEE proceedings C-generation, transmission and distribution, IET, vol. 127(4), pp. 228-239, 1980.

[16] M. Yee and J. Esztergalyos, "Ultra high speed relay for ehv/uhv transmission lines-installation-staged fault tests and operational experience," IEEE Transactions on Power Apparatus and Systems, vol. PAS-97(5), pp. 1814-1825, 1978.

[17] D. E. Hedman., "Propagation on Overhead Transmission Lines I-Theory of Modal Analysis," in IEEE Transactions on Power Apparatus and Systems, vol. 84(3), pp. 200-205, 1965.

[18] Makmur Saini, AA Zin, MW Mustafa, Ahmad Rizal Sultan, Rusdi Nur, "Algorithm for Fault Location and Classification on Parallel Transmission Line using Wavelet based on Clarke's Transformation," International Journal of Electrical and Computer Engineering (IJECE), vol. 8(2), pp. 699-710, 2018.

[19] F. V. Lopes et al., "Practical Methodology for Two-Terminal Traveling Wave-Based Fault Location Eliminating the Need for Line Parameters and Time Synchronization," in IEEE Transactions on Power Delivery, pp. 1-1, 2019.

[20] E. Khoudry, A. Belfqih, T. Ouaderhman, J. Boukherouaa, F. Faissal, "Multi-scale morphological gradient algorithm based ultra-high-speed directional transmission line protection for internal and external fault discrimination," International Journal of Electrical \& Computer Engineering (IJECE), vol. 9(5), pp. 3891-3904, 2019.

[21] S. Gautam and S. M. Brahma, "Overview of mathematical morphology in power systems - A tutorial approach," IEEE Power \& Energy Society General Meeting, Calgary, AB, pp. 1-7, 2009.

[22] C. Zhang, G. Song, T. Wang, L. Yang., "Single-ended Traveling Wave Fault Location Method in DC Transmission Line Based on Wave Front Information," IEEE Transactions on Power Delivery, vol. 34(2), pp. 2028-2038, 2019.

[23] J.-F. Rivest, P. Soille, and S. Beucher., "Morphological gradients," Journal of Electronic Imaging, vol. 2(4), pp. 326-337, 1993.

[24] L. Zhang, Y. ping Lv, H. Yin., "A multi-resolution morphology gradient based non communication protection scheme for transmission lines," in Electric Utility Deregulation and Restructuring and Power Technologies, 2008. DRPT 2008. Third International Conference on. IEEE, pp. 1608-1613, 2008.

[25] N. Kulkarni, S. Lalitha, S. Deokar., "Real time control and monitoring of grid power systems using cloud computing," International Journal of Electrical and Computer Engineering (IJECE), vol. 9(2), pp. 941, 2019. Available: 10.11591/ijece.v9i2.pp941-949.

[26] Elmahdi Khoudry, Abdelaziz Belfqih, Jamal Boukherouaa, Faissal Elmariami, Abdelmajid Berdai., "An Overview of Smart Grid Communication Networks Technologies, Protocols and Challenges," Proceedings of the 2nd International Conference on Networking, Information Systems and Security, ACM, pp. 25, 2019.

[27] F. Costa, B. Souza, and N. Brito, "Effects of the fault inception angle in fault-induced transients," IET generation, transmission \& distribution, vol. 6(5), pp. 463-471, 2012.

\section{BIOGRAPHIES OF AUTHORS}

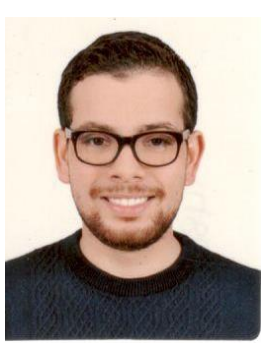

Elmahdi Khoudry is a Ph.D. student at the National Higher School of Electricity and Mechanics (University Hassan II of Casablanca- Morocco). His research activities concern power systems protection and automation as well as Smart Grids technologies.

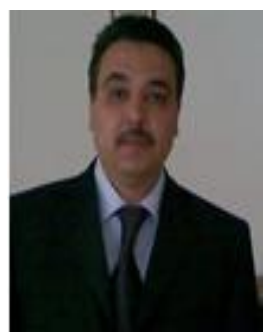

Abdelaziz Belfqih Professor at the National High School of Electricity and Mechanics (University Hassan II of Casablanca - Morocco). PhD, Engineer and holder of the University Habilitation searches (HDR). Head of the research team" Electrical Networks and Static Converters." Teacher researcher currently working on electricity network and smart grids. 


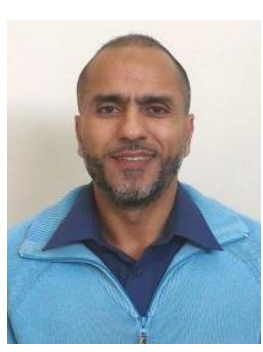

Jamal Boukherouaa Professor at the National High School of Electricity and Mechanics (University Hassan II of Casablanca - Morocco). PhD, Engineer and holder of the University Habilitation searches (HDR). Head of the research team" Electrical Networks and Static Converters." Teacher researcher currently working on high frequency static converters.

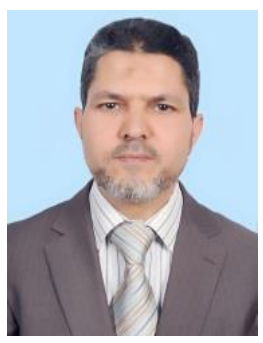

Faissal Elmariami Professor at the Superior National High School of Electricity and Mechanics (University Hassan II of Casablanca - Morocco). PhD, Engineer and holder of the University Habilitation searches (HDR). Head of the research team" Electrical Networks and Static Converters." Teacher researcher currently working on stability of the electricity network and smart grids. 